ISSN 1984-3755

Licenciado sob uma Licença Creative Commons

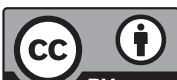

\title{
0 Concílio Vaticano II: a presença da Igreja no mundo em espírito de serviço, em especial aos mais pobres
}

\author{
Vatican II Council: the Church's presence in the world in \\ a spirit of service, especially towards the poorest
}

\section{Matias Martinho Lenz}

Doutor em Ciências Sociais pela Pontifícia Universidade Gregoriana, Roma; mestre em Sociologia da Religião pela Pontifícia Universidade Católica de São Paulo (PUC-SP); professor de Sociologia na Universidade do Vale do Rio dos Sinos (Unisinos); assessor da Pastoral Social da CNBB (1979-1981 e 2002-2007); reitor do Colégio Pio Brasileiro em Roma (1992-2000); assessor para a Ação Social da Província jesuíta em Porto Alegre, Porto Alegre, RS - Brasil, e-mail: martinholenz@uol.com.br

\section{Resumo}

No Vaticano II, a Igreja fez suas as alegrias e esperanças, tristezas e angústias dos homens de hoje, "sobretudo dos pobres e de todos aqueles que sofrem" (Cf. GS 1). Neste estudo, o autor trata o tema da pobreza e dos pobres no Concílio, em três momentos: no primeiro, situa o tema da pobreza e dos pobres, explicitando a compreensão dos padres conciliares sobre suas causas e as perspectivas de resposta a esse flagelo; no segundo, mostra em que direção avançou tal questão nas décadas que se seguiram ao Concílio, sobretudo na América Latina; no terceiro, procura apontar para iniciativas 
que poderiam fazer a Igreja avançar mais em uma ação pastoral na perspectiva da opção pelos pobres.

Palavras-chave: Igreja. Concílio. Mundo. Pobres.

\begin{abstract}
In Vatican II, the Church brought about its joys and hopes, sorrows and anxieties of man of today, "especially of the poor and of all those who suffer" (cf. GS 1). In this study, the author addresses the issue of poverty and the poor at the Council on three occasions: in the first, he addresses the issue of poverty and the poor, explaining the understanding of the fathers on their causes and the prospects of response to that scourge; in the second, he shows in which direction this issue has advanced in the decades after the Council, particularly in Latin America; in the third one, he attempts to point initiatives that could make Church advance more in the pastoral perspective of the option for the poor.
\end{abstract}

Keywords: Church. The Council. World. Poor.

\title{
Premissas
}

A convocação do Concílio Vaticano II por João XXIII deu-se na forma do novo e inesperado. Novo pelo seu caráter eminentemente pastoral, inesperado por não ter sido premeditado, mas fruto de uma inspiração que surpreendeu o próprio Papa. Recordemos as palavras de João XXIII, em seu discurso aos assistentes da Ação Católica Italiana, em 8/9/1959: "A ideia do Concílio não amadureceu como um fruto de prolongada consideração, mas como uma flor de inesperada primavera" (KLOPPENBURG, 1962, v. I, p. 12). Na verdade, não só o Concílio foi algo inesperado, como foram surpreendentes muitos de seus desdobramentos.

Esse foi, pela primeira vez na história, um Concílio eminentemente pastoral. “...O Concílio, mais do que das verdades divinas, se ocupou principalmente da Igreja, da sua natureza, da sua estrutura, da sua vocação ecumênica, da sua atividade apostólica e missionária”, como afirmou 
Paulo VI no Discurso de Conclusão do Concílio (DOCUMENTOS DO CONCÍLIO, 2004, p. 666). Na verdade, o que pode ser considerado como a grande novidade do Concílio, foi sua atitude para com o mundo, uma atitude não de condenação, mas de diálogo. Como disse o mesmo Papa, ela "interessou-se em perscrutar o mundo deste nosso tempo. Nunca talvez como no tempo deste Concílio a Igreja se sentiu na necessidade de conhecer, avizinhar, julgar retamente, penetrar, servir e transmitir a mensagem evangélica e, por assim dizer, atingir a sociedade humana que o rodeia, seguindo-a na sua rápida e contínua mudança" (DOCUMENTOS DO CONCÍLIO, 2004, p. 667).

Nesse diálogo, a Igreja fez suas as alegrias e esperanças, tristezas e angústias dos homens de hoje, "sobretudo dos pobres e de todos aqueles que sofrem"(GS 1). A aproximação ao mundo, especialmente dos pobres, buscou ser em espírito de serviço, adotando "a maneira de falar acessível e amiga, que é própria da caridade pastoral”, na formulação de Paulo VI, no citado discurso de encerramento (DOCUMENTOS DO CONCÍLIO, 2004, p. 670).

Nesse contexto, surgem algumas perguntas sobre o tema da pobreza e dos pobres no Concílio. Vou resumir as perguntas a três blocos, que serão as três partes desta minha reflexão: primeiro, qual foi a presença do tema da pobreza e dos pobres no Concílio? Qual a compreensão do Concílio sobre as causas da pobreza? Que remédios o Concílio propõe? Segundo, em que direção avançou essa questão nas décadas que se seguiram ao Concílio, sobretudo na América Latina? E terceiro, em que pontos seria possível avançar mais? Quais os desafios que nos coloca hoje o mundo dos pobres?

\section{A igreja dos pobres}

Uma das intuições fundamentais de João XXIII foi certamente a de buscar nos sinais dos tempos um lugar de encontrar Deus e a realidade do mundo.

Tanto no Concílio como nas encíclicas desse Papa, a leitura dos sinais dos tempos é lugar teológico muito frequentado. É um lugar de 
compreensão e diálogo, lugar de onde vêm os apelos mais intensos. Temas fortes nessa aproximação com o mundo foram o diálogo com o mundo moderno, a busca da unidade dos cristãos e a atenção ao mundo dos pobres e da pobreza na Igreja. Os comentaristas concordam em dizer que o tema dos pobres recebeu menos atenção que o diálogo e o ecumenismo. Mesmo assim, não faltaram apelos nem respostas a partir da problemática da pobreza e dos pobres, no mundo e na Igreja.

O primeiro impulso para se tratar tema dos pobres veio do próprio Papa João XXIII. O Papa Bom era também um papa de costumes simples, que nunca escondeu sua origem humilde, de família camponesa de Sotto il Monte, Bérgamo. Formara uma convicção pessoal profunda sobre a importância da pobreza como fonte de credibilidade para o testemunho cristão. Em mensagem de 11 de setembro de 1962 - exatamente um mês antes do início do Concílio - João XXIII referiu-se a esse assunto de uma forma que ficou marcada para sempre. Falou do serviço que a Igreja deve prestar ao mundo a partir da sua fé em Cristo, luz do mundo. Entre os pontos importantes nesse serviço, o Papa destacou a igualdade de todos os povos no exercício de seus direitos e deveres, a defesa da família, a necessidade de sair do individualismo e de assumir a responsabilidade social. E acrescentou: "Um outro ponto luminoso: face aos países subdesenvolvidos, a Igreja se apresenta como ela é e como ela busca ser, a Igreja de todos e particularmente a Igreja dos pobres" (ALBERIGO, 1985, p. 239).

Em que sentido João XXIII terá usado a expressão "Igreja dos Pobres"? A encíclica Mater et Magistra (1961), aparecida naquele período, pode oferecer-nos uma chave de compreensão. Destaco três aspectos. Primeiro, um sentido humano e realista da pobreza. Assim, diz o Papa que Jesus, "ao contemplar a multidão faminta", exclamou: "Tenho pena de toda essa gente" (Mc 8,2). Comenta o Papa: Jesus manifesta assim que ele "se preocupa com as exigências materiais dos povos", provando essa preocupação com os exemplos de sua vida, "multiplicando várias vezes o pão que havia de saciar a fome da multidão que o seguia" (MM 4). Aparece aqui a compreensão da pobreza como um problema político e social, e os pobres como víitimas de relações econômicas injustas. Ao falar dos critérios de justiça e equidade que devem reger a remuneração do trabalho, 
o Papa denuncia o "espetáculo tristíssimo de inumeráveis trabalhadores em muitas nações e continentes inteiros, os quais recebem um salário que os submete, a eles e às suas famílias, a condições de vida infra-humanas" (MM 65). Um terceiro aspecto: o Papa vê a saída da pobreza não no incentivo à esmola, mas em salários justos, adequação entre progresso econômico e social (MM 70), fortalecimento da "empresas artesanal, da exploração agrícola familiar e também da empresa cooperativista" (MM 82) e por fim, da cooperação internacional", face às "dimensões mundiais dos problemas humanos importantes” (MM 197-199). A visão de pobreza do Papa é, assim, marcada tanto pela compaixão e humanidade, quanto pela de suas causas e pelo empenho em transformações que alterem um quadro de injustiças. A pobreza real de milhões de pessoas, famílias e nações inteiras questionam a Igreja, desafiam-na a reencontrar-se consigo mesma, a renovar sua consciência eclesial e sua forma de presença com os pobres. Na Encíclica Pacem in Terris (1963), João XXIII aborda a pobreza no contexto dos direitos humanos e dos povos. Vê todo ser humano - rico ou pobre - como pessoa, de igual dignidade, sujeito de direitos e deveres (PT 8). Faz uma leitura dos sinais dos tempos. O primeiro sinal, enunciado pelo Papa, é "a gradual ascensão econômico-social das classes trabalhadoras". "Hoje, em toda parte, escreve o Papa, os trabalhadores exigem ardorosamente não serem tratados à maneira de meros objetos, à mercê do arbítrio alheio, mas como pessoas, em todos os setores da vida social, tanto na econômico-social, como na política e na cultura" (PT 40). Falar dos direitos e da necessidade de as nações desenvolvidas "a auxiliarem por todos os meios" (PT 123) as nações mais pobres, respeitando ao mesmo tempo a liberdade e as características de cada povo, "abstendo-se cuidadosamente de qualquer pretensão de domínio" (PT 125) soa hoje como extremamente atual.

A Igreja de Jesus Cristo é chamada a se posicionar diante da pobreza de vastas camadas da população, por vezes de maiorias dos habitantes de um país, frente a situações de exploração e de dominação. É chamada a ser a Igreja de todos, mas de ser especialmente a Igreja dos pobres. Essas palavras soam como palavras proféticas, pré-anunciando a opção preferencial pelos pobres, feita alguns anos mais tarde pelo episcopado latino-americano, opção assumida, mas tarde, pela Igreja universal. 


\section{0 tema dos pobres no Concílio}

Dentro do Concílio, o tema dos pobres e da pobreza não teve o destaque que um grupo de padres conciliares ligados à causa esperavam ou desejaram. Houve uma memorável intervenção na aula conciliar, na trigésima quinta Congregação Geral, no dia 06-12-1962, do Cardeal Jaime Lercaro, Arcebispo de Bologna (Itália). Segundo a crônica do então Frei Boaventura Kloppenburg, o Cardeal Lercaro "faz suas as propostas dos Cardeais Suenens e Montini. Depois disserta sobre o mistério de Cristo nos pobres" (KLOPPENBURG, 1962, v. II, p. 259). Para Lercaro, o tema dos pobres não é um dos tantos temas do Concílio. "O tema do Concílio é a Igreja enquanto ela é sobretudo a Igreja dos pobres" (ALBERIGO, 1985, p. 241). O Cardeal Lercaro lançou esse tema do ponto de vista teológico, a partir do mistério de Cristo no coração da Igreja. "O mistério de Cristo na Igreja - diz Lercaro - é sempre, e sobretudo em nossos dias, o mistério de Cristo nos pobres (ALBERIGO, 1985, p. 242). O Cardeal considera a ausência desse tema nos esquemas preparatórios como uma grave lacuna.

O foco dos pobres aparece, sobretudo, em três documentos do Concílio: Lumen Gentium (n. 8), Ad Gentes (n. 5) e Gaudium et Spes (especialmente na Segunda Parte, no cap. III, sobre a Vida Econômico-Social). São três as dimensões colocadas nesses textos: primeiro, nos pobres, reconhecemos a imagem do Senhor, presente no pobre e do que sofre; segundo, a pobreza como o caminho, seguido pessoalmente por Cristo, proposto por ele aos seus discípulos e que deve ser retomado pela Igreja peregrina, como um meio para dar testemunho autêntico do Evangelho; e, em terceiro lugar, o compromisso da Igreja de servir os pobres e de se empenhar na superação da pobreza injusta.

É interessante observar que, apesar de a expressão "Igreja dos pobres" ser defendida por um grupo de bispos, sobretudo do terceiro mundo (dentre os quais Dom Hélder Câmara), essa expressão não ocorre em nenhum texto conciliar. A expressão só voltará a um texto do ensino social na Encíclica Laborem Exercens, de João Paulo II, quando fala da solidariedade com os homens do trabalho.

Tal solidariedade deverá fazer sentir a sua presença onde a exijam a degradação social do homem-sujeito do trabalho, a exploração dos trabalhadores e as áreas 
crescentes de miséria e de fome. A Igreja acha-se vivamente empenhada nessa causa, porque a considera como sua missão, e como uma comprovação da sua fidelidade a Cristo, para assim ser verdadeiramente a "Igreja dos pobres" (LE 8).

É importante observar em que ótica o Concílio examina a questão da pobreza no mundo. Gaudim et Spes trata da questão já na primeira parte, no n. 8, no contexto dos desequilíbrios modernos: o desequilíbrio entre saber prático e o pensamento teórico (falta de sínteses satisfatórias), entre eficiência prática e exigências da consciência moral; desequilíbrio no interior da família (em virtude da pressão das condições demográficas, econômicas e sociais), desequilíbrio entre raças, grupos sociais e nações. O desequilíbrio entre nações ricas e pobres é percebido, em seu limite, como assimetria de poder, da ambição de propagar a própria ideologia ou fruto de egoísmos coletivos. Faltou nesse texto (e no Concílio) um diagnóstico sobre o colonialismo e sobre o que, nesses desequilíbrios, pode ser fruto do uso do poder dos mais fortes para explorar os mais fracos. Era um tema difícil de ser abordado quando muitos países europeus estavam envolvidos em guerras coloniais e quando o mundo se encontrava em plena Guerra Fria (pensemos na crise dos foguetes nucleares em Cuba, em 1962).

O tema da pobreza como fruto de injustiças entra na Gaudium et Spes não diretamente, mas de forma oblíqua. Não como afirmação dos padres conciliares, mas como constatação de que cresce nos pobres a consciência de que sua pobreza é fruto de injustiça e da má distribuição dos bens da terra e que essa visão dos pobres interpela as nações ricas. Cresce a consciência de que não é apenas necessário aumentar o domínio sobre as coisas, mas que é preciso "estabelecer uma ordem política, social e econômica que sirva cada vez melhor (o gênero humano) e ajude indivíduos e grupos a afirmar e desenvolver a própria dignidade" (GS 9). Segue o texto:

Daí vem a insistência com que muitos reivindicam aqueles bens de que, com uma consciência muita viva, se julgam privados por injustiça ou por desigual distribuição. As nações em vias de desenvolvimento e as de recente independência desejam participar dos bens da civilização, não só no campo político, mas também no econômico, com relação às outras nações mais ricas e de mais rápido progresso. Os povos oprimidos pela fome interpelam os povos mais ricos (GS 9). 
Essa interpelação se torna reivindicação das mulheres por "paridade de direito e de fato com os homens" e, da parte de operários e camponeses, não só ganhos mais justos, mas exigência de "participar na organização da vida econômica, social, política e cultural” (GS 9).

Subjacente a tudo isso, o Concílio vê "uma aspiração mais profunda e universal: as pessoas e grupos anelam por uma vida plena e livre, vida digna do ser humano, pondo ao próprio serviço tudo quanto o mundo de hoje lhes pode proporcionar em tanta abundância" (GS 9). Tudo isso, conclui o Concílio, leva a humanidade a se interrogar, a examinar a raiz desses desequilíbrios no desequilíbrio fundamental do homem que se afastou de Deus, se impregnou de materialismo prático e que sofre uma profunda divisão em si mesmo. Questionando a tendência do homem moderno de querer bastar-se, o Concílio propõe como fundamento de um novo homem e uma nova sociedade a pessoa e a mensagem de Jesus Cristo.

A teologia do Concílio, em relação ao pobre e à pobreza, pode ser interpretada como a de um humanismo cristão (cf. influência da Jacques Maritain nas propostas sociais do Concílio). Essa visão transparece em muitas passagens de Gaudium et Spes. Citemos uma, que se tornou antológica. Propondo que a realização humana seja valorizada acima dos bens que o homem produz, o Concílio afirma:

O homem vale mais por aquilo que ele é do que por aquilo que ele possui. De igual modo, tudo que os homens fazem para conseguir maior justiça, mais fraternidade, uma organização mais humana das relações sociais, vale mais do que os progressos técnicos (GS 35).

O capítulo III da segunda parte da Gaudium et Spes aprofunda o tema da pobreza e dos pobres, numa visão humanista. Dentre as inquietações que nos assaltam está a consciência de que, enquanto aumentam as riquezas, agravam-se as desigualdades, que chegam em algumas partes a formas de "desprezo dos pobres". Coexistem o luxo e a miséria, no interior dos países e entre as nações (cf. GS 63). O Concílio critica as doutrinas liberais que se opõem às necessárias reformas. Entre essas, o Concílio ressalta a reforma agrária, fundamentando-a na exigência que a terra cumpra sua função social e aprove a expropriação de terras para fins de reforma agrária, mediante justa compensação (GS 71). Volta a 
condenar as excessivas desigualdades e a "dependência indevida" (mais uma vez, sem falar de exploração).

Como caminho das ações a empreender, o Concílio retoma os grandes princípios do ensino social da Igreja. Pede que a vida econômica e social promova "a dignidade e vocação integral da pessoa humana e o bem de toda sociedade" (GS 63). Inspirada pelo desejo de servir a todos (GS 89), a Igreja pede a conversão do coração: obedecendo a Cristo e buscando primeiramente o Reino de Deus, o fiel "recebe daí um amor mais forte e mais puro, para ajudar a seus irmãos e realizar, sob o impulso da caridade, a obra da justiça" (GS 72). Essa obra da justiça se realiza penetrando de espírito cristão a vida da comunidade política de cada país, na busca ativa do bem comum, e, em nível mais amplo, promovendo a paz e construindo a comunidade internacional em novas bases.

Nos pobres, Jesus Cristo nos interpela:

o próprio Cristo como que apela em alta voz para a caridade dos seus discípulos. Não se dê aos homens o escândalo de haver algumas nações, geralmente de maioria cristã, na abundância, enquanto outras não têm sequer o necessário para viver e são atormentadas pela fome, pela doença e por toda espécie de miséria. Pois o espírito de pobreza e de caridade são a glória e o testemunho da Igreja de Cristo (GS 88).

Como expressão de serviço a todos, especialmente aos mais pobres, o Concílio faz recomendações e propostas. Propõe que se reforce a cooperação internacional, condena a corrida armamentista, reclama uma profunda "reforma das mentalidades" (do belicismo para paz), apoia o fortalecimento dos organismos internacionais e sugere a "criação de uma autoridade pública mundial, que seja por todos reconhecida, e com poder suficiente para que fiquem garantidos a todos a segurança, o cumprimento da justiça e o respeito dos direitos" (GS 82). Propõe normas práticas para a cooperação internacional.

No final, a Gaudium et Spes faz propostas muito concretas para a ação social da própria Igreja. Louva a ação dos voluntários, sobretudo jovens, que se oferecem espontaneamente para ajudar outros homens e povos. Eles devem ser ajudados. Depois, exorta todo povo de Deus a aliviar a miséria do próximo, "não somente com o supérfluo, mas também 
com o necessário" e pede aos bispos que, nessas ações, precedam o povo "com a palavra e o exemplo".

O Concílio faz mais duas propostas: que se organize a atividade social e caritativa nas dioceses (assim como nas nações e no mundo), com espírito ecumênico, "conjugando a atividade dos católicos com a dos outros irmãos cristãos”, coordenando meios e forças (GS 88). Lembrando mais uma vez os pobres, o Concílio propõe a criação de um organismo da Igreja para fomentar "o progresso das nações necessitadas e a justiça social entre as nações” (GS 90), proposta que deu origem às Pontifícias Comissões Justiça e Paz.

A Igreja de todos, especialmente dos pobres, será assim uma Igreja servidora. Como diz o Pe. Almeida, em seu livro sobre a Lumen Gentium (ALMEIDA, 2005, p. 111), “o Vaticano II consagrou a Igreja do serviço. Ela se coloca a serviço do homem", de todos os homens. O Concílio nos recorda que esse espírito de serviço se aprende na escola de Jesus de Nazaré. "Não se nasce com espírito de serviço, comenta ainda o Pe. Almeida. É necessário contrariar tendências egoístas, enraizadas em nossa natureza [...]" (ALMEIDA, 2005, p. 112). Conclui o Concílio, na Gaudium et Spes: "lembrados da palavra o Senhor: 'nisto todos conhecerão que sois meus discípulos, se vos amardes uns aos outros' (Jo 13,35), os cristãos nada podem desejar mais ardentemente do que prestar serviço aos homens e mulheres do mundo de hoje, com generosidade maior e mais eficaz".

\section{Em que direção caminhou a igreja dos pobres: sua recepção na América Latina}

A presença do terceiro mundo, especificamente da América Latina, dentro do Concílio, foi modesta. Em contraste, pode-se dizer que o impacto do Concílio no nosso continente foi notável, revelando uma Igreja viva e aberta aos apelos de renovação, lançados pelo movimento conciliar.

De fato, o peso dos representantes de países da Europa foi preponderante: $3 / 4$ dos postos das comissões eram ocupados por europeus. $\mathrm{Na}$ consulta realizada pela Comissão antepreparatória junto ao episcopado do mundo, a resposta dos bispos da América Latina foi significativa. No 
Brasil, 79\% dos bispos responderam. Como nos constata Beozzo em suas pesquisas históricas, apareceram duas tendências, também presentes no Concílio: uma, de renovação e diálogo; outra, de conservadorismo e condenação. Entre os pedidos feitos pelos bispos abertos aparecia: uso da língua vernácula na liturgia e maior atenção aos pobres. A ala conservadora sentiu-se respaldada pela tendência prevalecente na Cúria Romana. Nesse contexto, é importante ressaltar a figura carismática de João XXIII, sonhando uma Igreja renovada, uma Igreja dos pobres, ajudando com seu carisma aos padres conciliares a superar a dissociação que se havia criado entre a proposta de aggiornamento, pedida pelo próprio Papa e os esquemas extremamente conservadores elaborados sob supervisão da Cúria e felizmente rejeitados pelo plenário dos padres conciliares e substituídos por 17 esquemas, que finalmente resultaram nos 16 Documentos do Concílio.

A recepção desses documentos e do espírito renovador do Concílio, em muitas Igrejas particulares, foi intensa, ativa e criativa. O surdo clamor das massas empobrecidas se transforma em um grito de resistência e exigência de transformação. Medellín constata uma irrupção dos pobres na Igreja. Na sociedade, essa irrupção toma a forma da afirmação de antigas etnias dos indígenas e a tomada de consciência dos afrodescendentes, no surgimento de movimentos de resistência aos governos ditatoriais, nos anos 1970 e no florescer de movimentos sociais nos anos 1980. Na categoria Igreja, dois movimentos eclesiais prepararam essa recepção: o movimento bíblico, que coloca a palavra de Deus nas mãos do povo e a renovação litúrgica, que conduziu a toda uma inculturação da Liturgia nas línguas e culturas dos povos.

Duas luzes vieram somar-se à renovação trazida pelo Concílio: a publicação da Encíclica Populorum Progressio, a grande encíclica do Papa Paulo VI sobre o desenvolvimento dos povos com justiça social e a difusão da Mensagem dos bispos do Terceiro Mundo (publicada em agosto de 1967), assinada por 18 bispos, dentre os quais nove brasileiros. O texto reflete sobre o desfio que a pobreza de grande parte da humanidade coloca para a Igreja. Foi um forte incentivo à elaboração de uma teologia da libertação.

Porém, os grandes momentos de recepção do Concílio pela Igreja da América Latina foram as três Conferências do Episcopado Latino-americano: Medellín, Puebla e Santo Domingo. 
Medellín procurou ler os sinais dos tempos na América Latina, à luz dos documentos do Concílio. Percebe o desejo de libertação como um surdo clamor que vem dos pobres (MEDELLÍN, Pobreza, 2). A grande intuição foi ver a Igreja como sacramento universal de salvação num mundo pobre e de maiorias empobrecidas, isto é, maiorias tornadas pobres por um sistema iníquo. Essa Igreja quer ser pobre com os pobres. Coloca-se face a face à pobreza inumana (MEDELLÍN, Pobreza, 1). Analisa a pobreza nos seus efeitos, mas sobretudo nas suas causas, para buscar suprimi-las. Denuncia a pobreza injusta e o pecado que a engendra (MEDELLÍN, Pobreza, 5). Busca o rosto de uma Igreja autenticamente pobre, missionária e pascal, na expressão de Gustavo Gutierrez. Nesse rosto, a virtude da pobreza voluntária ganha um novo sentido de solidariedade e compromisso com os pobres, o caminho da pobreza evangélica (AG 5). Depois de Medellín, multiplicaram-se experiências de engajamento e ações solidárias de Igrejas locais, de comunidades cristãs e de famílias religiosas.

Puebla retoma e aprofunda essa caminhada. Afirma a necessidade de conversão de toda Igreja, em vista de uma opção preferencial e evangélica pelos pobres. Santo Domingo vê, além disso, a importância de resgatar a cultura do povo pobre, nas suas ricas e variadas expressões.

Os documentos de Medellín e Puebla fizeram uma leitura contextualizada da realidade do povo majoritariamente pobre do continente latino-americano e do Caribe. Seguindo um esquema proposto por Gustavo Gutierrez, podemos distinguir três perspectivas fundamentais nessa leitura: foi uma leitura a partir de Cristo; ressaltando seu caráter missionário e revelando sua dimensão pascal.

A perspectiva cristológica: a questão dos pobres, nesses documentos, é vista numa perspectiva à luz da pessoa e missão salvífica de Cristo (MEDELLÍN, Pobreza, 7). Como havia afirmado o Concílio, "A Igreja reconhece nos pobres e nos que sofrem a imagem de seu fundador" (LG 8; cf. Mt 25,31-46). Na esteira desse texto, o tema central da reflexão sobre a Igreja dos pobres é a identificação de Cristo com os pobres. Não se trata apenas de uma dimensão de sua mensagem, mas referência à identificação mais profunda do pobre como sinal do reino de Deus. O texto mais expressivo dessa compreensão talvez seja a passagem de Puebla sobre os rostos do Cristo sofredor na América Latina. 
O caráter missionário da Igreja dos pobres: a missionariedade da Igreja é dimensão central da comunidade cristã. Medellín afirma a urgência dessa missão, para todos (MEDELLÍN, Pobreza), mas, de maneira privilegiada, a favor dos pobres. A boa-nova anunciada aos pobres é um dos sinais da chegada do Reino em Jesus, um anúncio encarnado e inculturado. Para muitos setores da Igreja, a ida aos pobres começou com a descoberta do mundo dos pobres, a entrada em um mundo de misérias e de esperanças (veja a sugestiva obra de Pedro Trigo, La Cultura Del Barrio, Fundação Centro Gumilla, Caracas, 2005 - mostrando as possibilidades de humanização qualitativa da cultura suburbana). Nessa busca, deu-se o encontro com outras Igrejas que também se encontravam nesse caminho, nascendo daí um novo tipo de diálogo ecumênico e na criação de serviços ecumênicos a favor dos pobres.

A maior riqueza nesse campo foi a afirmação do potencial evangelizador dos pobres. Medellín viu a comunidade cristã de base como "núcleo primeiro e fundamental da Igreja" (Medellín, Pastoral de Conjunto, 10). As experiências das CEBs "ajudaram a Igreja a descobrir o potencial evangelizador dos pobres" (CONSELHO EPISCOPAL LATINO-AMERICANO CELAM, 2004, p. 1147). Os destinatários privilegiados da mensagem do Reino são também seus portadores. Puebla saúda as CEBs como o fato mais importante da vida da Igreja na América Latina e como "expressão do amor preferencial da Igreja pelos pequenos" (CELAM, 2004, p. 643). Nas CEBs o povo encontra espaço para participar das tarefas eclesiais e no engajamento pela transformação do mundo. As comunidades de base são manifestação do povo messiânico: os últimos serão os primeiros.

A Igreja dos pobres como um anúncio pascal: anunciar o Evangelho num mundo de pobreza significa testemunhar a vida numa realidade de morte. Para Medellín, a Igreja dos pobres é uma Igreja pascal, lembrando a figura e missão do servo sofredor (Is 40). Anunciar a vida significa ajudar a libertar os pobres das muitas situações de morte injusta e prematura: da fome, da violência, da doença e da repressão. A libertação integral acontece também aqui pela vitória sobre a raiz dessas situações de morte que é o pecado, o egoísmo e o acúmulo de bens. Sem confundir planos e tarefas, essa leitura revela a consciência do caráter global da libertação (na linha do humanismo integral do Concílio). Ao mesmo tempo, há consciência de que a libertação integral não é algo plenamente realizável agora, mas 
a luta pela libertação integral é uma forma de romper com o egoísmo, fomentando o sentido de fraternidade, de comunhão e de partilha.

A busca da libertação integral é parte da Missão de Cristo, que veio para libertar os homens "de todas as escravidões às quais os pecado os sujeita” (MEDELLÍN, Justiça, 3). Nessa perspectiva, a morte pode ser testemunho de vida. Poucas coisas são tão perigosas como defender a vida na América Latina. O martírio marcou e mudou a Igreja na América Latina. A Igreja dos pobres inquieta os grandes desse mundo e contesta seus privilégios. Ela se encontra com a cruz de Cristo, livremente aceita. Por isso mesmo, a Igreja dos Pobres não é triunfalista, e sim, pascal e celebrativa. A coragem até o derramamento do sangue, sangue de mártires (AG 5; 24) é anúncio da vitória do Ressuscitado. Cumprindo sua missão de evangelizar os pobres, dia AG, “a Igreja, movida pelo Espírito Santo, deve seguir o mesmo caminho de Cristo: o caminho da pobreza, da obediência, do serviço e da imolação própria até à morte, morte de que ele saiu vencedor pela sua ressurreição" (AG 5,2). Gutierrez sintetiza sua visão da opção pelos pobres na Igreja Latino-americana nessa afirmação: “A opção preferencial pelos pobres é uma opção teocêntrica: a fé no Deus de Jesus Cristo é a razão primeira e mais importante dessa opção" (GUTIERREZ, 1982a, p . 256). Não é um caminho seguido por toda Igreja, não é um compromisso abraçado por todos. Fatos e forças massivas atuam em sentido contrário. Mas não é isso que conta. O que conta é ser esse um caminho rico e fecundo, um caminho no seguimento de perto do Cristo pobre e sofredor e que ajuda a toda Igreja a confrontar-se com o rosto do pobre, com o qual Cristo se quis identificar, de forma inequívoca.

A recepção do Concílio Vaticano II no Brasil, sob o impulso de Medellin e Puebla, ultrapassou as expectativas. "Foi vivida como uma graça e uma tarefa eclesial primordial”, nas palavras de Beozzo (2005, p. 364). Sem entrar numa análise detalhada (feita já por diversos autores), limito-me aqui a duas observações, e que se ligam de algum modo ao tema da Igreja dos Pobres.

A primeira é recordar a convicção, formada entre grande parte dos bispos brasileiros presentes ao Vaticano II, que o Concílio não era um ponto de chegada, mas um ponto de partida. Daí decorreu uma firme determinação de levar adiante o Plano de Pastoral de Conjunto (1965), em 
continuidade do "Plano de Emergência" (1962). Contrariamente ao que aconteceu em muitos países da Europa, em que o Concílio se converteu num ajuste de contas com o passado, no Brasil o Concílio foi visto "como uma grande oportunidade para enfrentar os desafios do presente e do futuro, reinventado de certo modo a Igreja, com comunidades de base e pastorais populares" (BEOZZO, 2005, p. 362).

A outra observação toca mais diretamente ao tema da pobreza e da Igreja dos pobres. Um grupo de bispos brasileiros, em torno de 40, procurou dar continuidade às redes criadas ou aprofundadas durante o Concílio, especialmente um grupo chamado "Igreja dos Pobres", que celebrou a Eucaristia numa catacumba, presidida por D. João Batista Motta e Albuquerque, Arcebispo de Vitório, ES, e que adotou o "Pacto da Igreja Servidora e Pobre", um pacto de 13 pontos, dentre os quais o de viver uma "vida de pobreza segundo o Evangelho", promover obras sociais "baseadas na caridade e na justiça" e apoiar políticas públicas, também em nível internacional, "que permitam as massas sair da sua miséria". Comprometeram-se ainda de divulgar essas resoluções junto aos seus diocesanos (BEOZZO, 2005, p. 364-366).

Sabemos que nem tudo correu como planejado, não só por fraqueza humana, mas - como ainda revela Beozzo - pelo empenho de Roma de desfazer essas articulações. Por ordem superior foi abortado o projeto das "jornadas internacionais por uma sociedade superando as dominações", iniciado pela CNBB, sob o impulso de Dom Cândido Padim, e que havia recebido apoio de conferências episcopais da Europa, da Ásia e da América.

\section{Em que sentido é possível avançar mais}

$\mathrm{Na}$ conclusão da Gaudium et Spes, os padres conciliares tiveram o cuidado de advertir que a doutrina proposta por eles "reveste intencionalmente, em muitos pontos, apenas um caráter genérico". A razão disso, afirma o texto, é que "se trata frequentemente de realidades sujeitas a constante transformação".

No seu discurso de conclusão do Concílio, Paulo VI quis acrescentar uma consideração fundamental e definidora de uma nova atitude: "toda 
essa riqueza doutrinal orienta-se apenas a isto: servir o homem em todas as circunstâncias da sua vida, em todas as suas fraquezas, em todas as suas necessidades. A Igreja declarou-se como que escrava da humanidade... A ideia do serviço ocupou o lugar central" (DOCUMENTOS DO CONCÍLIO, 2004, p. 671).

Em base a essa visão do Concílio e essa orientação do Magistério, coloca-se para nós a pergunta: que novos desdobramentos a realidade nos aponta, em especial em relação ao mundo dos pobres? Quais as novas formas de pobreza ou exclusão a que o neoliberalismo, a globalização e a financeirização da economia nos conduzem?

As últimas encíclicas sociais, Sollicitudo Rei Socialis e Centesimus Annus são ricas em reflexões e trazem avanços notáveis em matéria de compreensão das novas realidades, que atingem a vida de todos, sobretudo dos pobres. Ainda assim, deixam abertas algumas lacunas. Apresento alguns exemplos. Um é a questão ecológica. Tratava-se de uma das lacunas mais sentidas nos documentos do Vaticano II. Os tempos não estavam maduros. Os temas dominantes eram outros: o crescimento das nações subdesenvolvidas e a luta pelos direitos humanos. O primeiro grande alerta global sobre os problemas do meio ambiente foi o relatório do Clube de Roma, "Os limites do Crescimento", publicado em 1972 e que caiu como uma bomba sobre a consciência dos povos. A primeira encíclica social que trata da questão ecológica é Sollicitudo Rei Socialis. Nesse documento, João Paulo II, muito sabiamente, liga a ecologia e a defesa do meio ambiente com o problema do consumismo. "O homem tomado mais pelo desejo do ter e do prazer, do que pelo de ser e crescer, consome de maneira excessiva e desordenada os recursos da terra e da própria vida" (SRS 37).

À raiz dessa desordem está o esquecimento de que o homem é administrador e não dono dos bens da natureza, colocados por Deus à sua disposição: "em vez de realizar seu papel de colaborador de Deus na sua obra da criação, o homem substitui-se a Deus e desse modo acaba de provocar a revolta da natureza, mais tiranizada que governada por ele" (SRS, n. 37). A análise até aqui está perfeita, mas infelizmente ficou incompleta. Não há menção, por exemplo, que os grandes poluidores são as nações ricas, que se dizem desenvolvidas, e que o projeto de querer manter e ainda ampliar o alto padrão do consumo não é compatível com 
a sustentabilidade do planeta Terra. Nem se fala dos efeitos danosos do desequilíbrio ambiental que atingem mais as camadas pobres, mais expostas e desprotegidas diante dos danos ambientais.

Outro avanço foi a identificação de uma realidade que a encíclica chama de "estruturas de pecado". Ficando firme que o pecado tem sempre uma dimensão pessoal, esse conceito deixou claro que o ser humano "está fortemente condicionado também pela estrutura social em que vive, pela educação recebida e pelo ambiente" (SRS 38). Uma importante consequência desse reconhecimento é que a ação social do cristão não pode esgotar-se na busca da conversão do coração, mas deve avançar na direção da luta política, em que se decide a mudança das estruturas de pecado, que são fruto do pecado e por sua vez induzem ao pecado (consequência que fica implícita na Encíclica). Há esforços para identificar novas dimensões da questão social, com os desdobramentos do sistema do capitalismo neoliberal, que produz novas formas de pobreza e gera massas de excluídos.

A Comissão Social dos Bispos da França produziu (maio de 2005) um documento em que buscam analisar criticamente o sistema econômico neoliberal, à luz da ética social cristã. Os bispos constatam que o sistema, gerador de exclusão, de sofrimentos de vastas camadas da população e de crescente desigualdade social, parece repousar apenas sobre a lei do mais forte. É um sistema não só injusto, mas absurdo. Uma dimensão desse absurdo é o peso excessivo e o papel preponderante da finança no contexto da economia. A financeirização da economia e desenvolvimento de um mercado financeiro especulativo tem reflexos nocivos no sistema produtivo, pois leva os acionistas a exigir um rendimento muito elevado do capital investido, sem relação com a realidade da empresa. O resultado é a imposição de pressões por vezes dramáticas sobre a rentabilidade: cessação de atividades pouco lucrativas, supressão de empregos, transferência de empresas para países onde a proteção do trabalho é fraca ou inexistente (levando à superexploração do trabalho).

O documento critica também a especulação, que significa o divórcio entre a economia real e o jogo financeiro. A corrida especulativa, em vez de ser um conjunto de decisões perfeitamente racionais, descritas na economia liberal, revela um comportamento compulsivo dos agentes da Bolsa e a "vontade de enriquecimento sem projeto definido". Desligada de 
qualquer projeto criador de trabalho, a especulação é uma distorção grave do sistema, que passa a favorecer uma "avidez insaciável de riquezas em detrimento de um verdadeiro projeto de desenvolvimento". O relacionamento entre nações ricas e pobres, baseado nos princípios do neoliberalismo, leva a imposições dos países hegemônicos, sob a capa da liberdade total de comércio. Contra os excessos e distorções do liberalismo, o texto propõe um imposto mundial contra a pobreza e a manutenção do Estado como ator indispensável da economia. É preciso ir mais longe, dizem os bispos franceses, dando passos concretos na direção de uma mudança profunda de mentalidade. Por exemplo: investir em fundos éticos e não especulativos; comprar em lojas de comércio justo ou privilegiar produtos da economia solidária. O grande desafio consiste em dar novamente todo valor ao ser humano, ver a empresa como comunidade humana e o trabalho como missão que confere dignidade à pessoa humana.

A CNBB (2005, p. 73-97), no seu Documento 80 (Evangelização e Missão profética: novos desafios) aborda, no capítulo 3, "o compromisso da Igreja em favor da inclusão social” realiza uma análise aguda da exclusão e propõe o desafio ético de construir uma inclusão solidária. Entre os princípios e os valores comuns na luta contra a exclusão o texto ressalta o seguinte: "a valorização das atitudes e práticas de coragem e fidelidade dos mais pobres, nas suas lutas pela dignidade e justiça. Eles são os principais protagonistas de sua libertação" (CNBB, 2005, p. 88). $\mathrm{Na}$ atuação da Igreja, o documento recorda que "nos últimos 50 anos, (sobretudo) a partir do Concílio Vaticano II (1962-1965), sua intervenção se fez mais incisiva na defesa dos pobres e nos serviços da justiça e da solidariedade [...]".

Seguindo o exemplo de Cristo, ela quer tornar-se o Bom Samaritano, que atenda generosamente os homens e as mulheres deixados meio mortos na beira da estrada (CNBB, 2005, p. 92).

Numa perspectiva de esperança, o texto conclui vendo nos pobres de hoje "profetas contemporâneos que denunciam estruturas iníquas e o pecado social e anunciam novas relações sociais de solidariedade e fraternidade" (CNBB, 2005, p . 97). Os pobres e seus movimentos são os profetas do presente, anunciadores de um mundo que está nascendo, pela força de Cristo libertador, que sustenta a união dos fracos e excluídos. 
Termino com uma citação da recente encíclica de Bento XVI, Deus Caritas est, sobre o Amor Cristão (2006). Lembrando que a caridade é um dever da Igreja, afirma Bento XVI: "No seio da comunidade dos crentes não deve haver uma forma de pobreza tal que sejam negados a alguém os bens necessários para uma vida condigna" (BENTO XVI, 2006, n. 20).

\section{Referências}

ALBERIGO, G.; JOSSUA, J.-P. La Recption de Vatican II. Paris: Éd. du Cerf, 1985. ALMEIDA, A. J. de. Lumen Gentium: a transição necessária. São Paulo: Paulus, 2005.

BENTO XVI. Carta Encíclica Deus Caritas Est, sobre o Amor Cristão. São Paulo: Paulinas, 2006.

BEOZZO, J. O. A igreja do Brasil no Concílio Vaticano II (1959-1965). São Paulo: Paulinas, 2005.

CONSELHO EPISCOPAL LATINO-AMERICANO - CELAM. Conclusão da Conferência de Puebla. 13 ed. São Paulo: Paulinas, 2004.

CONFERÊNCIA NACIONAL DOS BISPOS DO BRASIL - CNBB. Evangelização e missão profética da igreja: novos desafios. São Paulo: Paulinas, 2005.

COMISSION SOCIALE DES ÉVÊQUES DE FRANCE. Repères dans une Économie Mondialisée. Paris: Éd. du Cerf; Fleurus-Mame, 2005.

DOCUMENTOS DO CONCÍLIO ECUMÊNICO VATICANO II - DCE. São Paulo: Paulus, 2004. (Col. Documentos da Igreja).

GÓMEZ DE SOUZA, L. A. Do Vaticano II a um novo concílio? 0 olhar de um cristão leigo sobre a Igreja. Rio de Janeiro: CERIS; São Paulo: Loyola, 2004. KLOPPEnBURG, F. B. Concílio Vaticano II. Petrópolis: Vozes, 1962. v. I a IV. LOPES GONÇALVES, P. C.; BOMBONATO, V. I. Concílio Vaticano II, análise e perspectivas. São Paulo: Paulinas, 2004. 
LORSCHEIDER, A. et al. Vaticano II: 40 anos depois. São Paulo: Paulus, 2005. MARTELET, G. Non dimentichiamo il Vaticano II. Torino: ELLEDICI, 2001. MEDELLÍN COMO VAMOS. Disponível em: <http://www.medellincomovamos. org/pobreza-y-desigualdad >. Acesso em: 2 nov. 2011.

TRIGO, P. Espiritualidad conciliar. México: Univ. Iberoamericana Puebla, 2003.

TRIGO, P. La cultura del barrio. Caracas: Universidad Católica Andrés Bello \& Fundación Centro Gumilla, 2005.

Recebido: 15/11/2011

Received: 11/15/2011

Aprovado: 02/02/2012

Approved: 02/02/2012 